\title{
Study on Structural Characteristics and Evolution of China Regional Investment Network
}

\author{
Xiaohong Chang and Lihong Chang
}

\begin{abstract}
This paper collected the data of listed companies and its largest shareholders in Shanghai Stock Exchange and Shenzhen Stock Exchange 300 Index from 2007 to 2013. The listed companies are divided by their locations at provincial level. In this paper the regional investment network is identified by the rationale and specification content, and analyzed the structure feature of China's regional investment network and its evolution based on the complex network theory. The results of our study indicate that China's regional investment network function is gradually improving, and the network connection is complete. Geographical adjacent provinces have more contact and easy to form subgroup after competition and recombination. Contact densities keep increasing both in subgroup and inter subgroup, but provinces contact in subgroup is more than inter subgroup. The polarization effect of regional spatial pattern is gradually weakened, the contact density decreases in the core area, the contact density of edge area inside, edge area and core area is gradually increasing, so the regional investment is developing coordinated and balanced.
\end{abstract}

Index Terms-Regional investment, evolution, complex network, topological structure.

\section{INTRODUCTION}

Regional investment as a process and behavior of investment capital, with the material environment of economic regions as the main carrier and the main purpose of obtaining investment benefit, is the guarantee for the normal development of the whole social and economic activities, and the main leverage standard for the formation and development of regional economy and productivity. Regional investment need follow the evolution laws of regional economic development. Since reform and opening, China has implemented regional development strategies based on the characteristics of China's economic growth, the strategy of West Development, the revitalization of northeast old industrial base, the rise of the central region and encourage the eastern region lead in development, for example, and formed overall strategy for realizing the mutual promotion and common development between regional (Zhao, 2007). China further formulated the strategy of "accelerating development" and "balanced development" in the Forth Plenary Session of the Eighteenth CPC Central Committee. Strengthening regional unification of economic development is related to the development of the whole national economy, and it is also an effective way to promote the rapid development of the whole economy. It can be said that China's

Manuscript received October 9, 2018; revised January 11, 2019.

Xiaohong Chang is with Beijing Wuzi University, Beijing, China (e-mail: changhlw@126.com).

Lihong Chang is with Beijing University of Agriculture, Beijing, China. regional coordination and interaction mechanism is gradually taking shape, industrial agglomeration and urban agglomeration development have become the dominant spatial form with the improvement of national macro-control and regional policies. What are the structural features of China's regional investment network in the stage of improving the overall social and economic level and implementing the balanced development strategy? With the passage of time, the structural features of the network have also changed. So, how has China's regional investment network structure evolved in recent years? Based on the complex network theory, this paper establishes the regional investment network among provinces based on the cross-shareholding of listed companies in Shanghai-Shenzhen 300 index, and studies the structural characteristics and evolution of China's regional investment network from a microscopic perspective.

Scholars have analyzed the pattern of regional economic differences, convergence mechanism and evolution law of regional economy from many angles. In the 1980s, China's regional economic present conditional convergence trends [1], but no sign of absolute convergence, located in the coastal provinces and cities present convergence trend [2]. The regional economic growth in China has the significant conditional convergence under the influence of the factors investment and growth process, but it does not appear conditional convergence under the influence of the geographical environment and policy factors (Rong-bin Wang, 2011). Since the 1990s, the overall gap between China regions has been significantly anisotropic, which is represented club convergence (Fang Cai et al., 2000; Yifu Lin et al., 2003). On the basis of testing the evolution trend of regional economic growth by convergence method, some scholars reveal the evolution trend of regional economic distribution from the time dimension. The markov chain principle can be used to analyze the time evolution trend of regional economic growth and the transfer law between different states, revealing the evolution trend of regional GDP per capita [3]. The introduction of spatial effect in the traditional markov chain and the construction of weighted markov chain provide a new perspective for studying the transformation of regional economic types and the formation of spatial agglomeration pattern (Xiaohong Tao, 2013). Geographical factors play an important role in the development of regional economy [4]. The development level of regional economy not only depends on the productivity development level of the province, but also is affected to the spillover effect or radiation effect of the economic development of the surrounding provinces to some extent [5]. Economic spillover effect exists between China's coastal areas and inland areas [6]. 
This paper constructed the regional investment network based on the research of regional economy and regional investment, and introduced the complex networks theory into the research of regional investment network structure and its evolution. This paper provides a new view for the research of regional economy and regional investment, at the same time, provides theoretical support for different regional economic coordinated development and regional investment strategy.

\section{ANALYSIS ON FORMATION OF REGIONAL INVESTMENT NETWORK AND INVESTMENT CHARACTERISTICS}

\section{A. Analysis on Formation Motivation of Regional Investment Network}

Economic relation between regions can strengthen or weaken spatial differences and promote dynamic changes in regional spatial patterns. At present, the study of urban spatial economic relations presents a research system combining with theory and empirical, qualitative and quantitative. Friedmann (1973) mainly studied the spatial organization theory of urban system through empirical analysis [7]. Schonharting et al. (2003) studied the spatial flow and the interaction between cities [8]. In the development of globalization, Taylor and Hoyler (2000) believed that the link between the world's high-end service enterprises promoted the link between world cities, which formed a complex urban network across the world and finally realized the development of globalization [9]. The fundamentally characterized different from global network, domestic regional investment network is geographical proximity between different provinces in China, and its cultural friction and transportation cost are far lower than global urban network (Kangjuan Lv et al., 2011).

The process of regional investment is the coupling of space aggregation and space diffusion (Yanjun Liu et al., 2006). The content of regional investment mainly includes people flow, logistics, information flow, capital flow and technology flow. The company is the microeconomic main part of the region, and the listed company is the core strength of company. The economic environment, market environment and innovation environment in the region play a core role in the development of listed companies. Meanwhile, the concentration and diffusion of resource, the innovation of infrastructure, the formation of industrial division system and urban construction contribute to the formation of regional investment network format. First of all, under the joint action of investment agglomeration -- diffusion mechanism, the regions where listed companies are closely connected and have convenient access to capital, technology, information and other resources present a tendency of rationalization of resource endowment, thus promoting the formation and optimization of regional investment network. Secondly, infrastructure is a general material condition for intra-regional and inter-regional investment relation. The more developed the economy, the closer the investment relation, the higher the requirements for infrastructure. Improved infrastructure plays a significant role in accelerating economic investment activities and promoting the evolution of regional investment network pattern (Wenwei Liu et al., 2013). With the continuous improvement of infrastructure, especially the innovation of transportation mode, regional investment relation have been greatly improved. The regions with poor accessibility of regional investment are constantly filled, the homogeneity of investment activities is gradually formed, and the regional investment network pattern is increasingly mature. Third, the region link by industrial relations. The region develops into a group with functions relatively prominent through government promotion and policy adjustment, and forms an interdependent industrial division system. The establishment of close cooperation between companies promoted the investment relations between regions, and form the regional cooperation carrier of industrial division. Fourth, urban construction leads to urban expansion and urban area increase, which makes the distance between regions continuously shorten (Dan He et al., 2008). Because of the approach of space and market, the companies search markets and resources in different function areas, which strengthen the space agglomeration of investment, can reduce the transaction costs, promote companies form scale economy, the industry relation inter-regional and intra-regional, and form regional investment network.

\section{B. The Economic Scale Characteristics of Province}

According to statistics, the economic aggregate of 31 provinces in China exceeded 63 trillion in 2013, that is, 31 provinces created national GDP over 63 trillion. But the status of these provinces in the domestic economy is not completely the same, according to the province's per capita GDP (Fig. 1) in 2007-2013, the economic development level of 31 provinces present ladder-like distribution. Beijing, Tianjin, Shanghai is the highest level provinces of domestic economic development and the per capita GDP of three municipalities has been far higher than other provinces. Jiangsu, Zhejiang, Inner Mongolia, Liaoning, Guangdong, Fujian and Shandong are located in the second level of economic development. Tibet, Yunnan, Gansu, Guizhou belong to the lowest level. Jilin, Shaanxi and other provinces are located in the third level. This economic structure is distribution characterized by small both ends and large middle. That is to say, the number of provinces which the highest and lowest level of economic development is small, and the number of provinces at the second level and the third level accounts for the vast majority, indicating that the overall level of economic development in China is gradually in a certain uniform state, and most provinces are developing in a balanced way.

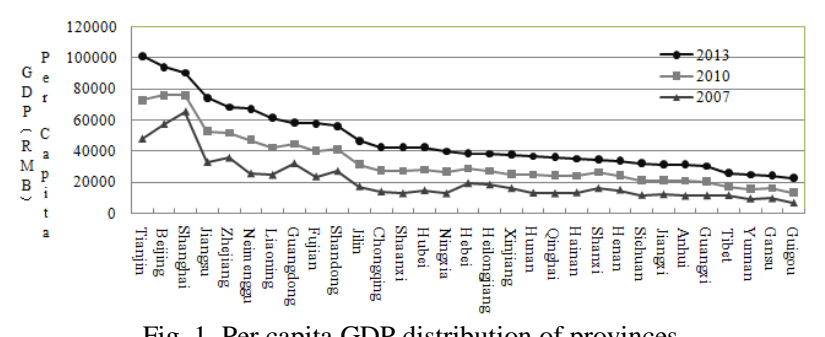

Fig. 1. Per capita GDP distribution of provinces.

\section{The Investment Scale Characteristics of Province}

This paper compares the fixed asset investment scale of each province in China from 2007 to 2013, and uses the investment effect coefficient to reveal the change degree of 
investment benefit of each province. Investment effect coefficient is the main index to evaluate macro-investment economic benefit. The formula is: Investment Effect Coefficient $=$ provincial GDP increment $/$ investment in the same period, which reflects the proportional relationship between GDP increment and social investment in the same period, and represents the regional GDP of unit investment increase (Zhenhuan Feng et al., 2000).

This index is used to explore the difference of economic development speed between provinces in China. It is found by calculation that China's regional investment benefit pattern is obvious. The investment effect coefficient of eastern provinces is high, and the investment effect coefficient of western provinces is low. The investment effect coefficient of provinces with high GDP is high, which indicates that the investment scale has a great impact on the development level of regional economy, and regional economic growth in China is highly dependent on investment. Therefore, it is particularly important to study the structural characteristics and evolution of regional investment network.

\section{ANALYSIS ON REGIONAL INVESTMENT NETWORK MODEL AND STRUCTURAL CHARACTERISTICS}

The interrelation between various stocks and stock holdings among listed companies makes the investment structure system and attribute characteristics of the securities market is a complex network of observable and quantifiable analysis. The development and evolution of investment network system can be studied by a more comprehensive way. Regional investment network is not like regular network with single characteristics, nor like random network with no rules. It reflected a complex network structure and statistical characteristics.

\section{A. Regional Investment Network Model Construction}

Regional investment network is a typical complex network of composing by various provinces, where capital and information resources continuously circulate among regions. This paper is based on the previous research (Yuanyuan Ma et al., 2011; Songling Yang et al., 2014), starting from the micro basis, selected the listed companies with mutual investment relations in the Shanghai and Shenzhen Stock Exchange 300 Indexes to establish a network, thus forming a matrix of provinces and listed companies based on shareholding relations, and then formed an investment relation network among provinces based on the location of the listed companies. According to the graph theory method, the regional investment network is abstractly described as a connected graph $\mathrm{G}: \mathrm{G}=(V, E)$, which consists of point set $V$ and edge set $\mathrm{E}$ composed of nodes in different provinces. $V=$ $\left\{v_{\mathrm{i}}, i=1,2, \ldots, \mathrm{n}\right\}, \mathrm{n}$ is the number of nodes in the network. $E=\left\{e_{\mathrm{i}}, i=1,2, \ldots, \mathrm{m}\right\}, \mathrm{m}$ is the number of edges in the network. The generation of edge set $E(\mathrm{G})$ is due to the investment relationship between provinces, which means that the they are connected, namely $a_{\mathrm{ij}}=1$ in the relational matrix and there is a edge from node $i$ to node $j$ in the regional investment network. If there is no investment relationship between the listed companies of $i$ province and $j$ province, $a_{\mathrm{ij}}=0$ in the relationship matrix and there is no edge from node $i$ to node $j$ in the regional investment network. At the same time, the direction of capital flow is defined as the direction of the edge.

CSMAR database and the Securities Web release listed companies cross-shareholdings from 2007 to 2013 as data sources, in order to study the complex network properties of listed companies cross-shareholdings of regional level, the regional investment network is as follows: (1) the main source of data is the CSMAR database and the Securities Web, collected information that the ownership relations and the company located between listed company, and construct the direction of the edge. (2) China has a total of 31 provinces, including municipalities and autonomous regions, in addition to Hong Kong, Macao and Taiwan, so there are 31 nodes when analyzing investment relations among provinces. (3) This paper selected the information of listed companies with cross-shareholding relations in 31 provinces from 2007 to 2013 to establish the cross-shareholding relationship matrix of listed companies. Then, according to the location of cross-shareholding listed companies, the regional investment relationship matrix of $31 * 31$ was further established to reflect the investment relationship between provinces.

\section{B. Topological Structure Analysis of Regional Investment Networks}

The topological property of a network refers to the nature of the network that does not depend on the specific position of nodes and the specific shape of edges. The corresponding structure is called the topological structure of the network (Jun Liu, 2009). The topological characteristics of complex networks have a great influence on the connectivity of networks. In this paper, the topological structure of China regional investment network is measured by means of measures such as degree centrality, average shortest path and agglomeration coefficient of the network.

In complex networks, network density can be used to measure the degree of interconnection between nodes in complex networks. According to the above relationship building regional investment network, the data analysis shows that China regional investment network connection increased from 93 to 112 , the network density increased from 0.1 to 0.12 in 2007, 2010 and 2007. The network of average density is small, and increased small, that China regional investment relations close degree increased gradually, but the whole remain relatively loose.

The centrality of nodes in a complex network can be described as the centrality of nodes in the network. Generally, the greater the degree of nodes, the stronger their centrality, and they enjoy a higher dominant position and priority choice. The mean centrality of china regional investment network increased from 4.903 to 6.065 , indicating that the intensity of china regional investment network links has significantly increased and its spatial structure is gradually optimized. From the regional characteristics of spatial distribution (Fig. 2). The centricity of most of provinces has increase different degree in addition to Yunnan, Xinjiang and other minority province, but the increasing amplitude is difference. The increase of centricity of Hunan province is most intense, its degree of centrality increased from 1 in 2007 to 8 in 2013. The 
second is Chongqing, its degree of centricity increased from 1 to 7 . This suggests that frequent spatial economic relation have made mutual investment across the distance. Some provinces had the potential to development actively establish investment contact with developed areas, strengthen the cooperation relationship between companies, and gradually become china regional investment network reserve power. The degree of centrality is still low in some provinces. More than half of the provinces have a degree of centrality less than 5 from 2007 to 2013, which indicates that there is still a great promotion of china regional economic relations. Due to the favorable environment, abundant resource elements, perfect infrastructure, reasonable industrial division system and urban construction, some traditional economically developed region such as Beijing, Shanghai and Guangdong, and their introversion centrality and extroversion centrality have ranked higher than other provinces. This reflects the core position of Beijing, Shanghai and Guangdong in china investment network. They are closely connected with the space economy connection of other provinces and play a certain aggregation effect and radiation effect. Qinghai, Tibet and other areas have been at the edge of the network due to their remote location and limited resources.

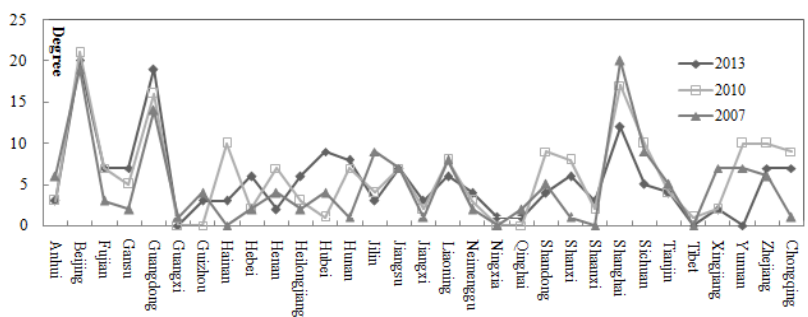

Fig. 2. Evolution of node centrality of the regional investment network(2007-2013).

\section{CONCLUSION}

This paper based on the cross-shareholdings behavior of listed companies of Shanghai and Shenzhen 300 index from 2007 to 2013 as samples, demonstrates the power of regional investment network, analyze microscopic motivation and investment characteristics of regional investment network. Based on the complex networks theory, by building a network model, empirical research on the structure features of china regional investment network and evolution through the degree of centricity. The main conclusions are as follows.

First, the spatial economic relation between regions has formed a pattern of fund flow between provinces. This kind of investment relation has resulted in spatial interaction between provinces, thus forming a regional investment network structure with provinces as nodes and investment relation between provinces as edges. Moreover, the change of time has affected the evolution of network structure. This paper constructed the regional investment network, and analyzed the structural characteristics of network topology, so as to analyze the typical characteristics of regional investment network structure and the evolution law.

Second, the overall density of china regional investment network is low, and the development of spatial economic connection is not perfect. The average connection degree between nodes is relatively small, and the function of investment network needs to be improved urgently. However, according to the data comparison from 2007 to 2013, the degree of network closeness is gradually increasing, and the network function is gradually improving. At the same time, regional investment network has a high aggregation coefficient, and the completeness of regional investment network has a relatively high degree. The network agglomeration coefficient presents decline, the regional investment relationship in China has balanced development trend, the investment gap lessen gradually, and the gap between the rich and the poor, between the developed areas and the underdeveloped areas shrinks gradually.

\section{ACKNOWLEDGMENT}

This research is supported by the 2016 Founded Project of Beijing Social Science Foundation (16YJC054,18LSC006).

\section{REFERENCES}

[1] B. Z. Chen and Y. Feng, "Determinants of economic growth in China: Private enterprise, education, and openness," China Economic Review, vol. 11, pp. 1-15, January 2000.

[2] M. Fujita and D. Hu, "Regional disparity in China 1985-1994: The effects of globalization and economic liberalization," The Annals of Regional Science, vol. 35, pp. 3-37, January 2001.

[3] D. Quah, "Galton's fallacy and test of the convergence hypothesis," The Scandinavian Journal of Economics, vol. 95, pp. 427-443, April 1993.

[4] L. J. Gallo, "Space-time analysis of GDP disparities among European regions: A Markov China approach," International Regional Science Review, vol. 27, pp. 138-163, February 2004

[5] S. J. Rey, "Spatial empirics for economic growth and convergence," Geographical Analysis, vol. 33, pp. 195-214, February 2001.

[6] L. G. Ying, "Understanding China's recent growth experience: A spatial econometric perspective," The Annals of Regional Science, vol. 37, pp. 613-628, April 2003.

[7] J. Friedmann, "The spatial organization of power in the development of Urban systems," Development and Change, vol. 4, pp. 12-50, March 1973.

[8] J. Schonharting, S. Alexander, and F. Andre, "Towards the multimodal transport of people and freight: Inter-connective networks in the RheinRuhr metropolis," Journal of Transport Geography, vol. 11, pp. 193-203, March 2003.

[9] P. J. Taylor and M. Hoyler, "The spatial order of European cities under conditions of contemporary globalization," Tijdschrift Voor Economische en Sociale Geografie, vol. 91, pp. 176-189, February 2000 .

Xiaohong Chang was born in Hebei Province, in 1982. She obtained her doctor of management and now is an associate professor of Beijing Wuzi University, Beijing, China. Her major field of study is regional economy.

Lihong Chang was born in Hebei Province, in 1984. She obtained her doctor of engineering, and now is a lecturer of Beijing University of Agriculture, Beijing, China. The major field of her study is regional project. 